\title{
Expression and immunolocalization of the calpain-calpastatin system during parthenogenetic activation and fertilization in the rat egg
}

\author{
K Haim, I Ben-Aharon and R Shalgi \\ Department of Cell and Developmental Biology, Sackler Faculty of Medicine, Tel Aviv University, Tel-Aviv, Israel \\ Correspondence should be addressed to R Shalgi; Email: shalgir@post.tau.ac.il
}

\begin{abstract}
Calpastatin is an intrinsic intracellular inhibitor of calpain, a $\mathrm{Ca}^{2+}$-dependent thiol protease. The calpain-calpastatin system constitutes one functional proteolytic unit whose presence and function has already been investigated in various cell types, but not in the egg. We have previously shown that calpain is expressed in rat eggs and is activated upon egg activation. The present study was designed to investigate the calpain-calpastatin interplay throughout the process.

Western blot analysis revealed two main calpastatin isoforms, the erythrocyte type $(77 \mathrm{kDa})$ and the muscle tissue type $(110 \mathrm{kDa})$. By immunohistochemistry and confocal laser scanning microscopy, we demonstrated that the $110 \mathrm{kDa}$ calpastatin was localized at the membrane area and highly abundant at the meiotic spindle in eggs at the first and second meiotic divisions. The $77 \mathrm{kDa}$ calpastatin isoform appeared to be localized as a cortical sphere of clusters. The 110kDa calpastatin and $\beta$-tubulin have both been localized to the spindle of metaphase II eggs, both being scattered all through the cytoplasm following spindle disruption by nocodazole treatment, implying a dynamic interaction between calpastatin and microtubule elements. Upon egg activation, membranous calpastatin translocated to the cortex whereas cortical millimolar (m)-calpain shifted towards the membrane. Spindle calpastatin and calpain remained static.

We suggest that calpastatin serves as a regulator of $\mathbf{m}$-calpain. The counter translocation of $\mathbf{m}$-calpain and calpastatin could serve as a means of calpain escape from calpastatin inhibition and may reflect a step in the process of calpain activation, throughout egg activation, that is required for calpain to exert its proteolytic activity.

Reproduction (2006) 131 35-43
\end{abstract}

\section{Introduction}

Sperm-egg interaction elicits a series of cellular events within mammalian eggs, leading to their activation. The initial event is a rapid elevation in intracellular calcium concentration $\left(\left[\mathrm{Ca}^{2+}\right]_{\mathrm{i}}\right.$ ) (Miyazaki 1988, Miyazaki et al. 1992), followed by $\mathrm{Ca}^{2+}$ oscillations (Miyazaki 1991, Fissore et al. 1992, Kline \& Kline 1992, Sun et al. 1992, Ben-Yosef et al. 1993). It had previously been suggested that the initial $\left[\mathrm{Ca}^{2+}\right]_{i}$ rise triggers completion of the second meiotic division (Ben-Yosef \& Shalgi 1998) and cortical granule exocytosis (CGE) (Ducibella 1991, Dandekar \& Talbot 1992) which results in modification of the zona pellucida (ZP) and hence in a block to polyspermy (Ducibella 1991, Kline \& Stewart-Savage 1994, Ben-Yosef \& Shalgi 1998).

Calpains belong to a highly conserved family of intracellular calcium-dependent thiol proteases (Dayton et al. 1976a, 1976b, Goll et al. 2003). There are two ubiquitously expressed isoforms, $\mu$ - and m-calpain, that differ significantly in the $\mathrm{Ca}^{2+}$ concentration required for their in vitro activation (micro or millimolar for $\mu$ - or $\mathrm{m}$-calpain respectively) (Goll et al. 2003). Since $\mathrm{Ca}^{2+}$ at a micromolar level is considered a supraphysiological concentration, several cellular mechanisms are suggested for lowering the $\mathrm{Ca}^{2+}$ concentration required for activation of calpain. Among these are: binding of calpain to membrane phospholipids; calpain autolysis, though intact calpain may be active as well; escape of calpain from its endogenous inhibitor, calpastatin, protein coactivators and phosphorylation (Michetti et al. 1991, Kuo et al. 1994, Arthur \& Crawford 1996, Melloni et al. 1996, Suzuki \& Sorimachi 1998, Barnoy et al. 1999, Tullio et al. 1999, Glading et al. 2002).

Calpain-mediated proteolysis of intracellular proteins is a key step in various cellular processes such as cytoskeleton modulation, cell migration, cell cycle progression and apoptosis (Carragher et al. 2002).

Calpastatin is a specific endogenous inhibitor of calpain which regulates calpain activity in vivo (Carragher et al. 2002, Goll et al. 2003) and is known to be restricted to 
vertebrates (Goll et al. 2003). There are eight different known isoforms of calpastatin (Geesink et al. 1998, Goll et al. 1999, Takano et al. 2000, Parr et al. 2001, Wei et al. 2002), most of which are ubiquitous while some are tissue specific (Melloni et al. 1998). It is assumed that different calpastatin isoforms inhibit different calpain isoforms within a single cell (Averna et al. 1999). Two main calpastatin isoforms are widely studied: the erythrocyte type $(\sim 77 \mathrm{kDa})$ and the muscle tissue type $(\sim 110 \mathrm{kDa})$ (Takano et al. 1991, 1993, Barnoy et al. 1999, Tullio et al. 2000).

The calpain-calpastatin system constitutes a functional proteolytic unit (Melloni \& Pontremoli 1989) in which calpastatin governs and fine tunes the calpain activity. For calpain to become fully activated, it should escape the inhibitory effect of calpastatin. Furthermore, it has been suggested that subcellular compartmentalization of either calpain or calpastatin may regulate calpain intracellular activity (Lane et al. 1992, Carragher et al. 2002).

Calpain participates in meiosis of Xenopus eggs and starfish oocytes (Watanabe et al. 1989, Santella et al. 1998), as well as of rat eggs (Ben-Aharon et al. 2005), presumably via cytoskeleton remodeling. However, this theory was challenged since it has been implied that calpain is capable of degrading c-mos product only in vitro, at supraphysiological calcium concentrations (Lorca et al. 1991).

The present study was devised to follow calpastatin expression and localization within the rat egg at various developmental phases, and to further elucidate the calpain-calpastatin interplay throughout egg activation.

\section{Materials and Methods \\ Collection of eggs}

For induction of ovulation, 23- to 25-day-old immature Wistar-derived female rats were injected with $10 \mathrm{IU}$ human chorionic gonadotropin (hCG; Sigma) 48-52 h after administration of $10 \mathrm{IU}$ pregnant mare serum gonadotropin (PMSG; Syncro-part, Sanofi, France).

\section{Eggs arrested at the metaphase of the first meiotic division (MI)}

Cumulus-enclosed oocytes at the MI stage were retrieved from antral follicles into Toyoda HEPES (TH) medium (Ben-Yosef et al. 1995) supplemented with $0.4 \%$ bovine serum albumin (BSA; Sigma) $8 \mathrm{~h}$ after hCG administration. Cumulus cells were removed mechanically. All manipulations were performed at $37^{\circ} \mathrm{C}$.

\section{Eggs arrested at the metaphase of the second meiotic division (MII)}

Eggs were isolated from the oviductal ampullae into $\mathrm{TH}$ medium supplemented with $0.4 \%$ BSA for immunofluorescence, or with $0.1 \%$ BSA for immunoblotting (Ben-Yosef et al. 1995), $14 \mathrm{~h}$ after hCG administration. Cumulus cells were removed by a brief exposure to hyaluronidase (400 IU/ml; Sigma).

\section{Fertilized eggs}

PMSG-hCG-primed immature females rats were mated with adult males. Eggs at various stages of fertilization were isolated at several time-points after mating. The earliest developmental stage classified was sperm binding (SB), 0-15 min after sperm attachment (Eliyahu \& Shalgi 2002), whereas the latest was the mitotic division.

\section{Parthenogenetic activation}

MII ovulated eggs were parthenogenetically activated, for $5 \mathrm{~min}$ in the dark, by calcium ionophore $(2 \mu \mathrm{M}$; ionomycim; Calbiochem, San Diego, CA, USA), followed by an additional 0 - or 20-min incubation in fresh $\mathrm{TH}$ medium lacking the activator, and then fixed.

\section{Meiotic spindle dissociation and recovery}

MIl eggs were exposed to nocodazole $(10 \mu \mathrm{g} / \mathrm{ml}$; Sigma $)$ for $1 \mathrm{~h}$ and were either fixed immediately or rinsed and incubated for an additional $30 \mathrm{~min}$ in fresh medium lacking the toxin.

\section{SDS-PAGE and Western blot analysis of proteins}

Batches of 500-700 cumulus-free MII eggs were lysed in 7-10 $\mu$ l lysis buffer (50mM Tris, pH 7.4, 1\% NP-40, $150 \mathrm{mM} \mathrm{NaCl}, 2 \mathrm{mM}$ EDTA, $1 \mathrm{mM} \mathrm{Na} V_{3} \mathrm{O}_{4}, 5 \mathrm{mM} \mathrm{NaF}$ and $10 \mu \mathrm{g} / \mathrm{ml}$ aprotinin (Sigma)). Proteins were separated by $10 \%$ SDS-PAGE at a constant current of $30 \mathrm{~mA}$ under reducing conditions, alongside marker proteins of known molecular weights (Amersham International plc, Amersham, Bucks, UK). Proteins were electro-transferred for $18 \mathrm{~h}$ at $40 \mathrm{~mA}$ onto a nitrocellulose membrane (Amersham), by a wet blotting apparatus (Hoeffer, San Francisco, CA, USA). Blots were incubated overnight at $4{ }^{\circ} \mathrm{C}$ with either monoclonal anti-calpastatin (1:750; Calbiochem) or polyclonal anti-calpastatin (1:100; Santa-Cruz Biotechnology, Santa Cruz, CA, USA) in blocking solution. Primary antibodies were recognized by horseradish peroxidase (HRP) conjugated to goat anti-mouse antibody (1:5000; Jackson Immunoresearch Laboratories, West Grove, PA, USA) or donkey anti-goat antibody (1:20 000; Santa-Cruz Biotechnology) respectively. Detection was performed by enhanced chemiluminescence (ECL; Supersignal; Pierce, Rockford, IL, USA). Myoblast extracts served as a positive control.

\section{Immunohistochemistry and confocal microscopy}

Eggs at appropriate developmental stages were fixed for $10 \mathrm{~min}$ at room temperature by $3 \%$ paraformaldehyde (Merck, Rahway, NJ, USA) in Dulbecco's phosphatebuffered saline (DPBS; Biological Industries, Beit Ha'emek, Israel), supplemented with $0.01 \%$ glutaraldehyde (Polysciences, Warrington, PA, USA). The eggs were then 
washed in a solution of 3\% fetal calf serum (FCS; Biological Industries) in DPBS (DPBS/FCS), which served as a blocking solution. ZPs were removed by $0.25 \%$ pronase (Sigma). ZP-free eggs were permeabilized for $10 \mathrm{~min}$ by $0.05 \%$ NP-40 (Sigma) in DPBS/FCS and washed with $0.005 \%$ NP-40 in DPBS/FCS. Permeabilized eggs were incubated for $2 \mathrm{~h}$ at room temperature in the presence of primary antibodies, washed in DPBS/FCS and reincubated for $30 \mathrm{~min}$ in the presence of fluorescent-labeled secondary antibodies. Chromosomal stage was detected by a DNAspecific fluorochome $(1 \mu \mathrm{g} / \mathrm{ml}$ Hoechst; Sigma). Eggs stained only with secondary antibody served as controls.

Primary antibodies were anti-77 kDa calpastatin mouse monoclonal antibody (1:200; Calbiochem), anti-110 kDa calpastatin goat polyclonal antibody (1:50; Santa-Cruz (R-19); sc-7561), anti-m-calpain mouse monoclonal antibodies (1:50; Calbiochem) and anti- $\beta$-tubulin mouse monoclonal antibody (1:7500; Sigma).

Fluorescent-labeled secondary antibodies (Jackson Immunoresearch Laboratories) were donkey anti-goat IgG-Cy3 (1:250), donkey anti-mouse IgG-Cy3 (1:1000 for $77 \mathrm{kDa}$ calpastatin; 1:250 for m-calpain) and donkey antimouse IgG-Cy2 (1:5000).

Calpastatin, $\beta$-tubulin, calpain and DNA were visualized and photographed by a Zeiss confocal laser-scanning microscope. The Zeiss LSM 410 (Oberkochen, Germany) is equipped with a $25 \mathrm{~mW}$ krypton-argon laser, a $10 \mathrm{~mW}$ helium-neon laser $(488,543$ and 633 maximum lines) and a u.v. laser (Coherent Inc. Laser Group, Santa Clara, CA, USA). A 40 NA/1.2 planapochromat water immersion lens (Axiovert $135 \mathrm{M}$; Zeiss) was used for all imaging. Co-localization analysis was performed on images of simultaneously detected calpastatin and $\beta$-tubulin using the Zeiss co-localization procedure (Talmor et al. 1998).

\section{Results}

\section{Expression of calpastatin isoforms in the rat egg}

Western blot analysis was preformed on extracts of MII eggs. We employed two calpastatin-specific antibodies which detect either the erythrocyte-type calpastatin isoform at $77 \mathrm{kDa}$ or the muscle tissue-type calpastatin isoform at $110 \mathrm{kDa}$ (Fig. 1). Both calpastatin isoforms were expressed in MII eggs. Extracts of myoblasts served as a positive control.

\section{Localization of the $77 \mathrm{kDa}$ and $110 \mathrm{kDa}$ calpastatin isoforms throughout egg activation}

Immunofluorescence confocal microscopy was used for tracking the intracellular distribution of calpastatin throughout egg activation. Eggs parthenogenetically activated by ionomycin were fixed at different time-points during the course of the second meiotic division. Calpastatin was highly abundant at the meiotic spindle (Fig. 2aB) and at the plasma membrane (Fig. 2aC) of MII eggs whereas the

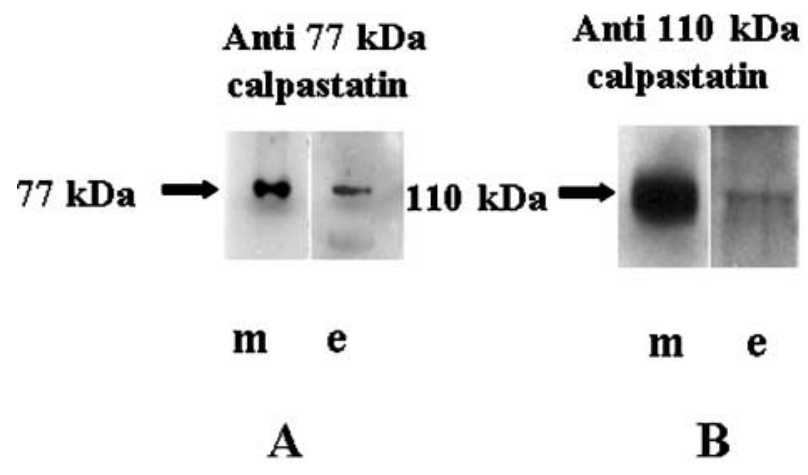

Figure 1 Expression of calpastatin isoforms in MII rat eggs. Proteins from lysates of $500(\mathrm{Ae})$ or $700(\mathrm{Be})$ eggs and of cultured myoblasts (control; Am; Bm) were resolved by SDS-PAGE analysis and transferred onto a nitrocellulose membrane for detection of the $77 \mathrm{kDa}$ and $110 \mathrm{kDa}$ isoforms. Blots were incubated overnight with either (A) mouse anti-calpastatin monoclonal antibody (1:750) or (B) goat anticalpastatin polyclonal antibody $(1: 100)$, followed by secondary antibodies-HRP-conjugated goat anti-mouse (1:5000) or HRP-conjugated donkey anti-goat $(1: 20000)$ respectively, and by an ECL detection system. The arrows indicate the calpastatin isoform bands at $77 \mathrm{kDa}$ and $110 \mathrm{kDa}$, as calculated from the migration of known protein standards.

labeling of the plasma membrane overlying the meiotic spindle was less intense. Immediately after exposure of the eggs to ionomycin, calpastatin displayed a mild translocation to the egg cortex (Fig. 2aF). This trend was further intensified 20 min after activation (Fig. 2al). Calpastatin labeling intensity at the spindle compartment did not change during all meiotic stages examined (Fig. 2aB, E and H). The $77 \mathrm{kDa}$ calpastatin isoform appeared to be localized as a cortical sphere of clusters (Fig. 2b), which did not change during activation (not shown).

\section{Possible interaction of the $110 \mathrm{kDa}$ calpastatin isoform with the spindle microtubules}

Eggs were double stained with anti-calpastatin and anti- $\beta$ tubulin prior to immunofluorescence confocal microscopy in order to demonstrate co-localization of calpastatin and microtubules. Co-localization (Fig. 3C) of both calpastatin (Fig. 3A) and $\beta$-tubulin (Fig. 3B) to the meiotic spindle was depicted in MII eggs. To further correlate the association of calpastatin with the spindle microtubules, we used $10 \mu \mathrm{g} / \mathrm{ml}$ nocodazole to obliterate the spindle structure. Nocodazole treatment resulted in scattering of both calpastatin and tubulin all through the cytoplasm (Fig. 3D-F). Once the toxin was rinsed off, the spindle was reconstituted with both calpastatin (Fig. 3G) and $\beta$-tubulin (Fig. $3 \mathrm{H}$ ) localized to it (Fig. 3I).

\section{Calpastatin localization at early stages of meiosis and at fertilization}

Calpastatin distribution in $\mathrm{MI}$ and MIl eggs was followed by immunofluorescence confocal microscopy. Calpastatin staining appeared intense at the meiotic spindle of $\mathrm{MI}$ and MIl eggs (Fig. 4B and E respectively) as well as at the 
(a)

$110 \mathrm{kDa}$ calpastatin

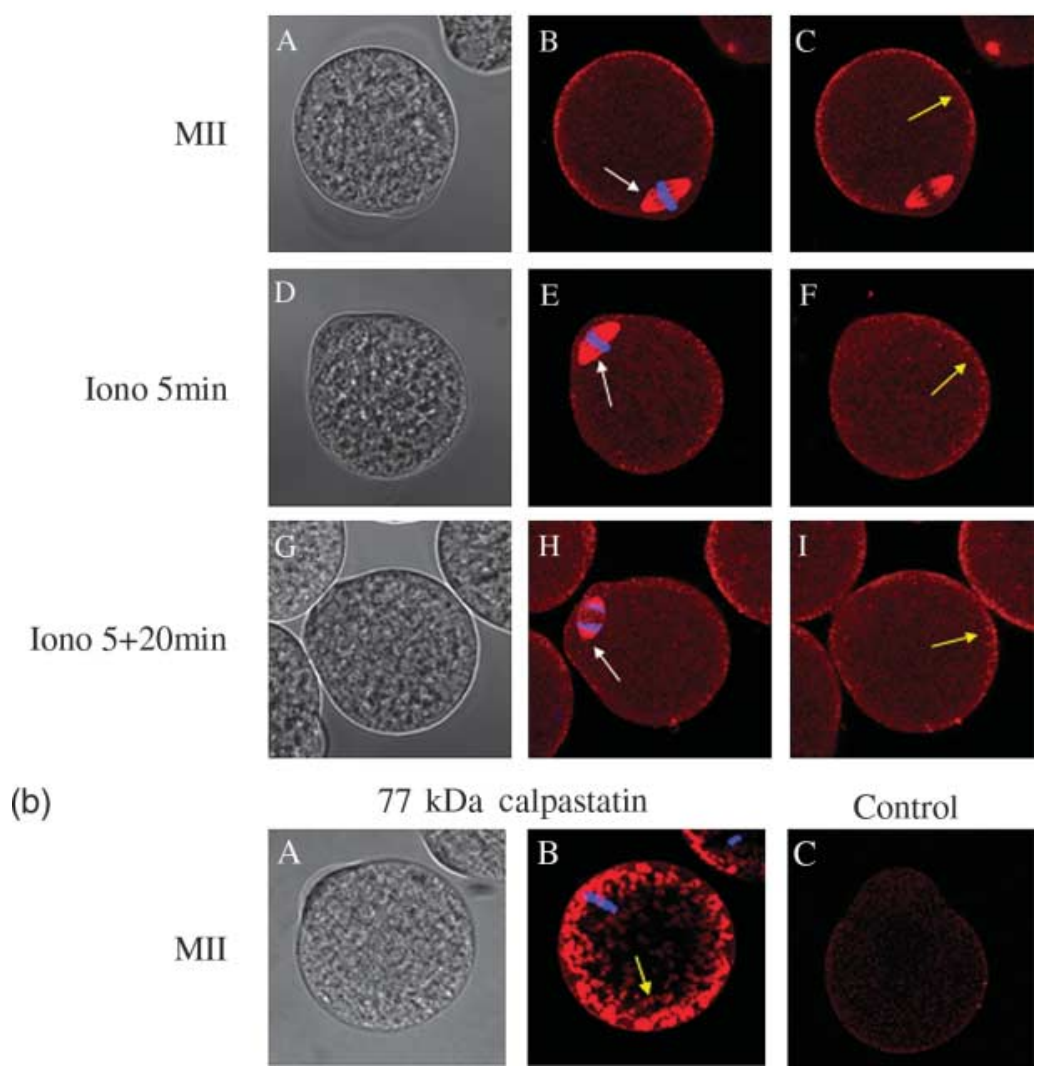

Figure 2 (a) Localization of $110 \mathrm{kDa}$ calpastatin in MII eggs and in parthenogenetically activated eggs. MII eggs (A-C), eggs treated for 5 min with ionomycin ( $2 \mu \mathrm{M}$; lono), washed and fixed shortly after activation (D-F), or 20 min after activation (G-I). Primary antibody (goat anticalpastatin (1:50)) was followed by a fluorescent labeled Cy-3 secondary antibody (1:250; red). DNA was labeled by Hoechst (1:1000; blue). Calpastatin and DNA were visualized by confocal laser-scanning microscopy. Light microscopy (A, D and G). Cross-sections through the egg meiotic spindle (B, E and H). Cross-sections at the equatorial plane of the egg (C, F and I). Egg meiotic spindle (white arrow). Calpastatin translocation from egg membrane towards the cortex (yellow arrow). Bar $=10 \mu \mathrm{m}$. (b) Localization of $77 \mathrm{kDa}$ calpastatin in MIl eggs. MII eggs (A-B) were incubated with primary antibody (mouse anti-calpastatin (1:200)) followed by a fluorescent labeled Cy-3 secondary antibody (1:1000; red). DNA was labeled by Hoechst (1:1000; blue). Calpastatin and DNA were visualized by confocal laser-scanning microscopy. Light microscopy (A). Cross-sections at the equatorial plane of the egg (B). Control MII egg incubated with secondary antibody only (C). Calpastatin localization as a cortical sphere of clusters (yellow arrow). Bar $=10 \mu \mathrm{m}$.

plasma membrane (Fig. 4C and F respectively). Furthermore, fertilized eggs that had been fixed at an early stage of fertilization (SB stage) exhibited a pattern of distribution resembling that of $\mathrm{MI}$ and $\mathrm{MII}$ eggs (Fig. $4 \mathrm{H}$ and $\mathrm{I}$ ) respectively. At later stages of fertilization the pattern of calpastatin localization (Fig. 4L) resembled the pattern in parthenogenetically activated eggs (Fig. 2l) where marked cortical staining was demonstrated with no significant change in the meiotic spindle staining (Fig. 4K).

\section{Intracellular localization of calpain throughout parthenogenetic activation}

In order to investigate the interaction between calpastatin and calpain, we immunostained parthenogenetically activated eggs with anti- $\mu$ - and anti-m-calpain antibodies. As previously demonstrated (Ben-Aharon et al. 2005), $\mu$-calpain had been localized to the meiotic spindle, as well as to the plasma membrane of MII eggs (not shown) and no change in its localization was observed during any stage of the egg activation process. m-calpain was specifically localized to the meiotic spindle (Fig. 5B) and to the cell cortex (Fig. 5C) of MII eggs. However, mild yet significant translocation of $\mathrm{m}$-calpain to the plasma membrane was observed immediately after exposure to ionomycin (Fig. 5F), which was further intensified at later stages of meiosis (Fig. 5l). No significant alteration in the intensity of $\mathrm{m}$-calpain staining at the spindle was observed throughout egg activation (Fig. 5E and $\mathrm{H}$ ).

\section{Discussion}

As shown in most of the cells studied, calpain co-exists along with its endogenous inhibitor, calpastatin. Although there is some evidence for a possible role of calpain as a cell cycle regulator in Xenopus eggs (Watanabe et al. 1989) or during cytoskeletal remodeling for reinitiating 


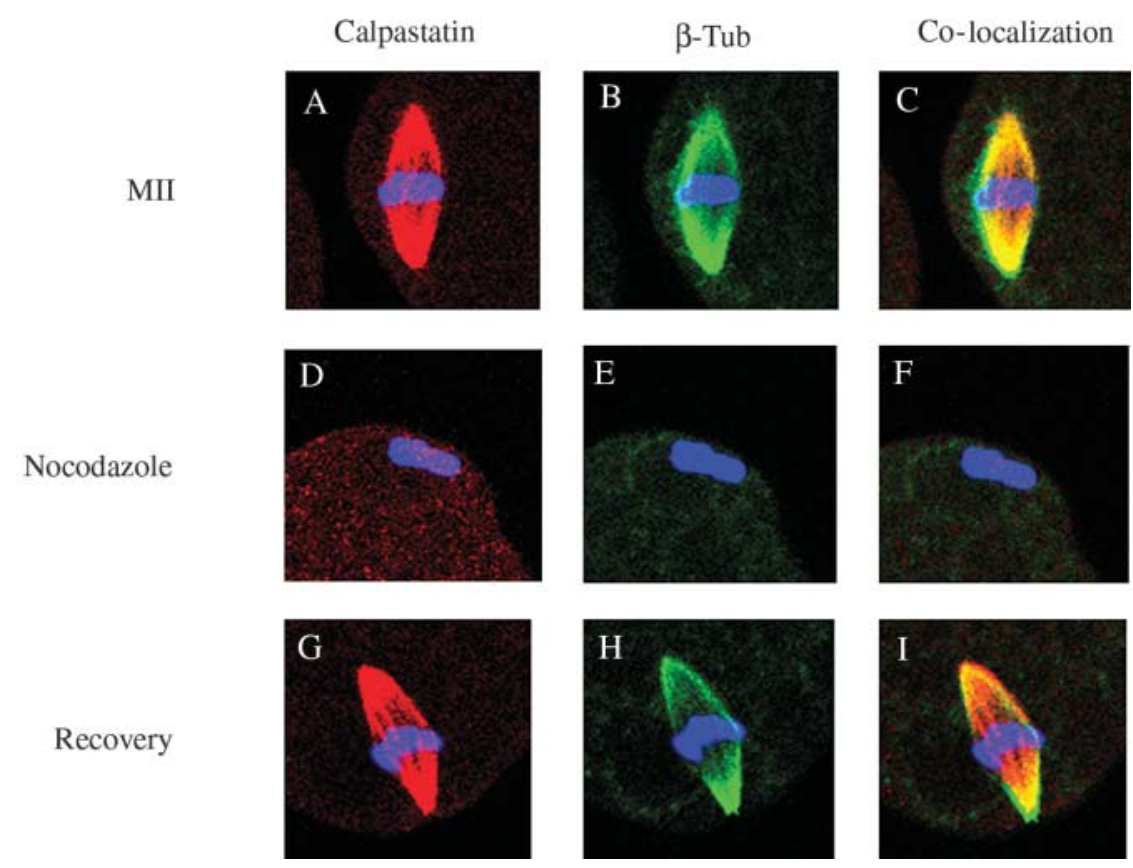

Figure 3 Co-localization of $110 \mathrm{kDa}$ calpastatin and $\beta$-tubulin ( $\beta$-Tub) in MII eggs before, during and after spindle disruption by nocodazole. MII eggs (A-C), nocodazole $(10 \mu \mathrm{g} / \mathrm{ml})$-treated MIl eggs fixed immediately after treatment $(\mathrm{D}-\mathrm{F})$, or after a 30-min recovery period (G-l). Primary antibodies (goat anti-calpastatin (1:50) and mouse anti- $\beta$-tubulin (1:7500)) were detected by the two appropriate fluorescent labeled Cy secondary antibodies (Cy-3 (1:250; red) and Cy-2 (1:5000; green) respectively). DNA was labeled by Hoechst (1:1000; blue). Calpastatin (A, D and G; red), $\beta$-tubulin ( $\mathrm{B}, \mathrm{E}$ and $\mathrm{H}$; green) and co-localization ( $\mathrm{C}, \mathrm{F}$ and $\mathrm{I}$ ) and $\mathrm{DNA}$ (blue) were visualized by confocal laser-scanning microscopy. Cross-sections through the egg meiotic spindle $(\mathrm{A}-\mathrm{I})$. Bar $=10 \mu \mathrm{m}$.

meiosis in starfish oocytes (Santella et al. 1998), there are no data regarding either expression of calpastatin or function of a calpain-calpastatin system in mammalian eggs. We therefore aimed, in the present study, to characterize the calpain-calpastatin system in mammalian eggs.

Calpastatin has been documented in various tissues of diverse vertebrates where it is expressed concomitantly with calpain (Goll et al. 2003). Calpastatin is considered to be responsible for monitoring and fine-tuning calpain activity, thus regulating the calpain-calpastatin network (Murachi 1989, Wei et al. 2002). Several studies indicate that calpastatin is comprised of various isoforms with varying molecular weights (Wei et al. 2002). To date, eight different isoforms have been identified (Geesink et al. 1998, Goll et al. 1999, Takano et al. 2000, Parr et al. 2001, Wei et al. 2002). Frequently more than one is expressed in a single tissue (Melloni et al. 1998). We detected the expression of the erythrocyte-type $(77 \mathrm{kDa})$ and the muscle tissue-type $(110 \mathrm{kDa})$ calpastatins in rat eggs, which correlated with the calpastatins reported in other tissue types (Takano et al. 1991, 1993, Barnoy et al. 1999, Tullio et al. 2000).

Calpastatin localization varies in the different tissues and is affected by biochemical modifications such as phosphorylation (Lane et al. 1992, Averna et al. 2001). It has been proposed that $\left[\mathrm{Ca}^{2+}\right]_{i}$ controls the amount of calpastatin available for calpain inhibition at the different cellular compartments, thus serving as a mechanism for regulating calpain activity (Averna et al. 2001). In the current study, immunofluorescence combined with confocal microscopy revealed a distinct cortical localization of the $77 \mathrm{kDa}$ isoform while the $110 \mathrm{kDa}$ calpastatin was mostly abundant at the meiotic spindle of eggs arrested at the MI as well as the MII stage. The $110 \mathrm{kDa}$ isoform also appeared to be localized to the plasma membrane, but not at the area overlying the MII spindle. This segment of membrane is known to be devoid of microvilli, rich in microfilaments and actin (Eliyahu et al. 2005) and is probably associated with different proteins from the rest of the membrane. Soon after the $\left[\mathrm{Ca}^{2+}\right]_{i}$ rise during egg activation, either sperm or parthenogenetically induced, calpastatin translocates from the plasma membrane towards the egg cortex, while its localization to the spindle remains unchanged.

In our previous study, we have allocated both $\mu$ - and $\mathrm{m}$-calpain to be localized to the egg cortical area as well as to the spindle region (Ben-Aharon et al. 2005). m-calpain but not $\mu$-calpain exhibited a dynamic change in its localization throughout egg activation by translocating from the cortical region to the membrane, shortly after the rise in $\left[\mathrm{Ca}^{2+}\right]_{i}$. We have determined a correlation between calpain activation and egg activation and inferred a role for $\mathrm{m}$-calpain in the process of sperm or parthenogenetically induced egg activation. We therefore speculated that 


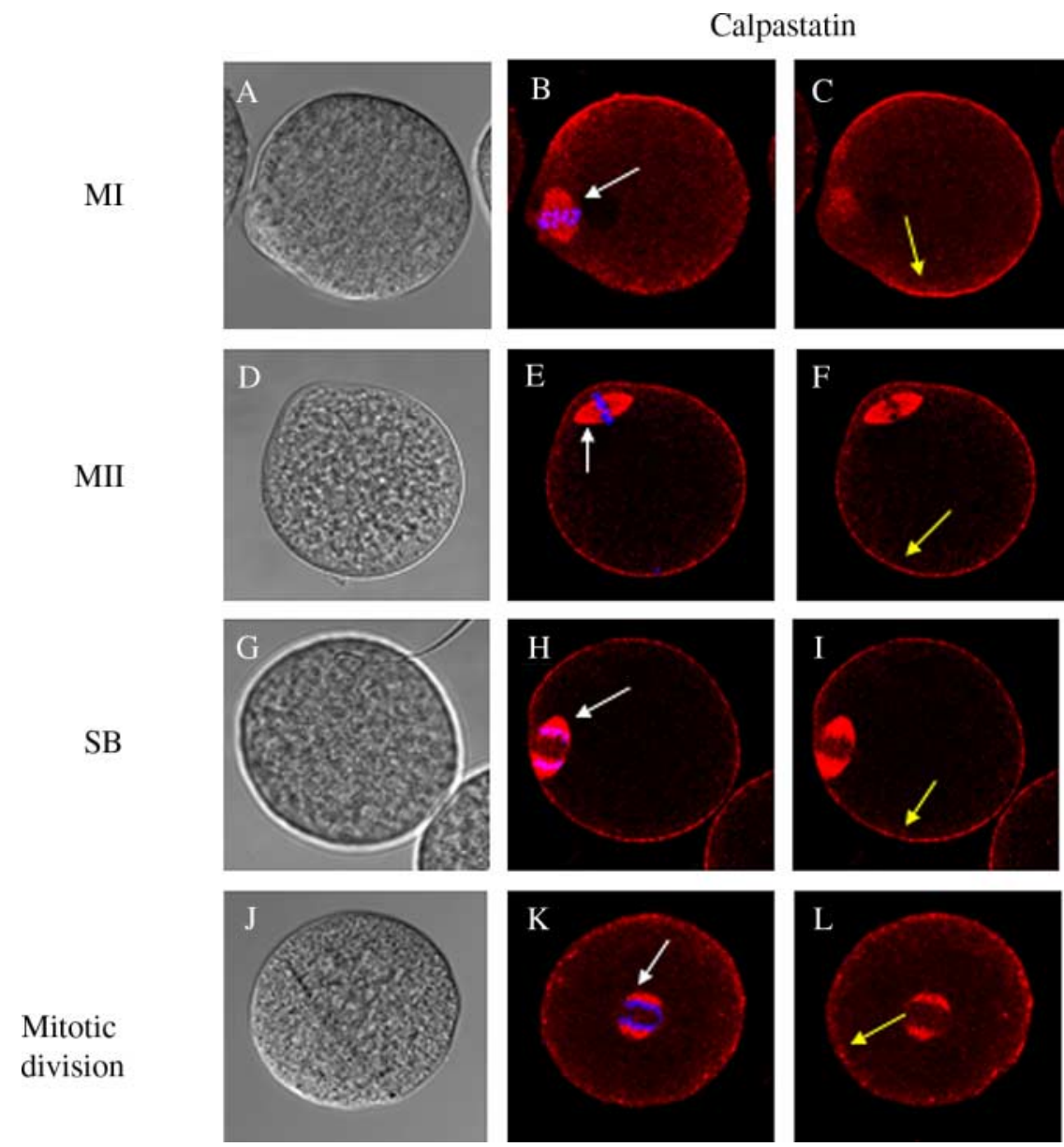

Figure 4 Localization of $110 \mathrm{kDa}$ calpastatin during various developmental stages. MI (A-C) and MII (D-F) eggs, early (SB; G-I) and late (J-L) fertilization stages. Primary poly antibody (goat anti-calpastatin (1:50)) was detected by a fluorescent labeled Cy-3 secondary antibody (1:250; red). DNA was labeled by Hoechst (1:1000; blue). Calpastatin and DNA were visualized by confocal laser-scanning microscopy. Cross-sections through the egg meiotic spindle $(\mathrm{B}, \mathrm{E}, \mathrm{H}$ and $\mathrm{K})$. Cross-sections at the equatorial plane of the egg $(\mathrm{C}, \mathrm{F}, \mathrm{I}$ and $\mathrm{L})$. Light microscopy $(\mathrm{A}, \mathrm{D}, \mathrm{G}$ and J). Egg meiotic/mitotic spindle (white arrow). Calpastatin translocation from egg membrane towards the cortex (yellow arrow). Bar $=10 \mu \mathrm{m}$.

$\mu$-calpain does not play an active role during this process but rather functions as a bystander or a backup system for $\mathrm{m}$-calpain. As a housekeeping gene product, $\mu$-calpain is expressed within the egg. It is quiescent during the early phase of fertilization, but may participate later during early cleavages. Calpain inhibition hinders completion of meiosis and lends credence to a model in which calpain activation is required for the cytoskeletal elements of the meiotic spindle to allow chromatid segregation. Calpain may be involved in the CGE as well, since inhibition of calpain resulted in CGE of a lesser extent (Ben-Aharon et al. 2005). Deducing the possible substrates of calpain upon the localization that has been demonstrated and the functional studies that have been performed using calpain inhibitors, we may imply a role for calpain in mediating cytoskeletal remodeling throughout both major pathways that occur during egg activation-completion of meiosis and CGE. The interaction between calpain and the cell cytoskeletal components has been well established in other cell types, where calpain mediates disassembly of the microtubule lattice (Pettigrew et al. 1996) and interacts with microtubule-associated proteins, two known favorable calpain substrates (Billger et al. 1988, Fischer et al. 1991, Johnson \& Foley 1993, Alexa et al. 1996). However, in the mammalian egg, the interplay between calpain and microtubule elements should still be elucidated.

Because of the close proximity of calpastatin and calpain (Goll et al. 2003) and the association of calpain with cytoskeletal structures we further studied the relationship of calpastatin with cytoskeletal components. We double stained MII eggs for calpastatin and tubulin, during spindle disruption by nocodazole and after a recovery period. The results revealed co-localization of both proteins upon depolymerization and repolymerization of the spindle microtubules. These results may imply a dynamic interaction between calpastatin and spindle microtubule elements. Localization of $\mathrm{m}$-calpain and its possible association with cytoskeletal structures in the vicinity of either the spindle or the plasma membrane may provide a 


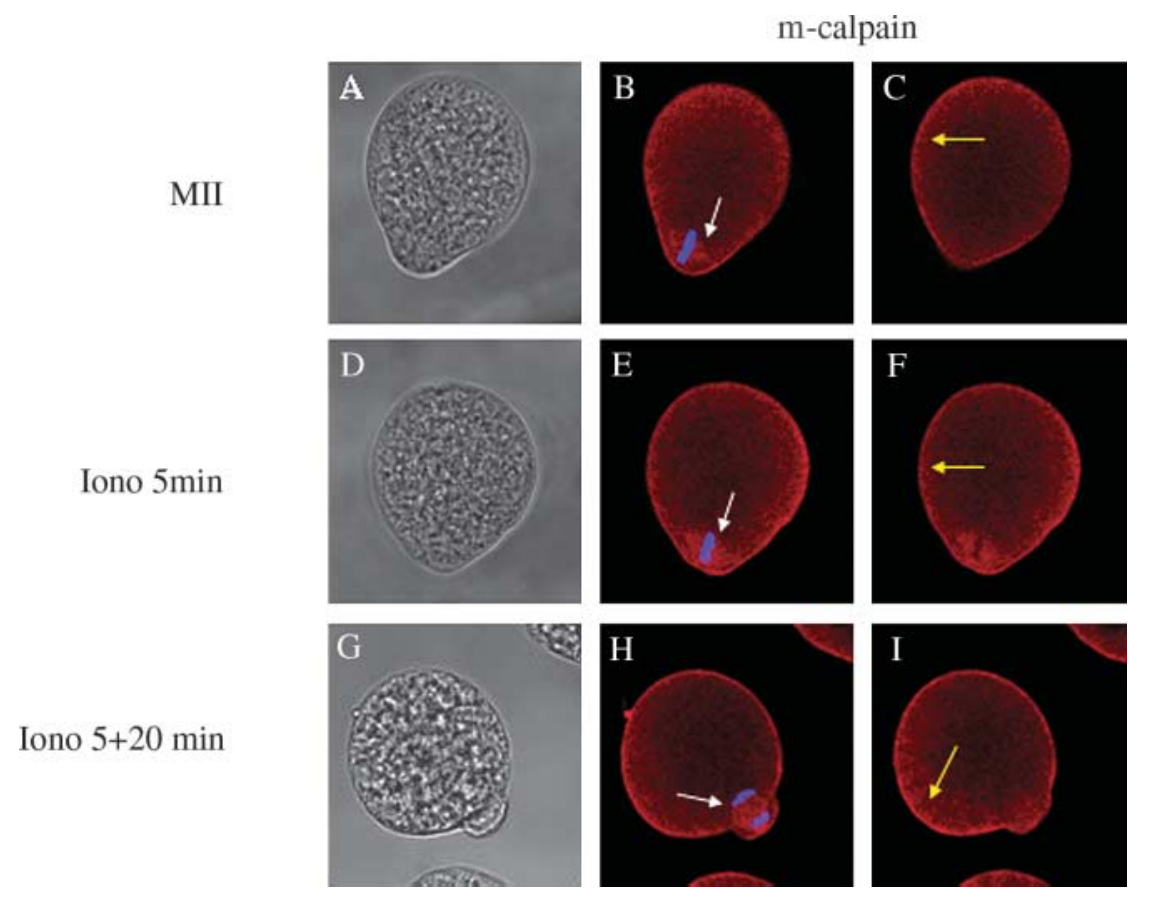

Figure 5 Localization of $\mathrm{m}$-calpain in MII eggs and upon parthenogenetic activation. MII eggs (A-C), eggs treated for 5 min with ionomycin ( $2 \mu \mathrm{M}$; lono), washed and fixed shortly after activation (D-F), or $20 \mathrm{~min}$ after activation (G-I). Primary antibody (mouse anti-m-calpain (1:50)) was followed by a fluorescent labeled Cy-3 secondary antibody (1:250; red). DNA was labeled by Hoechst (1:1000; blue). m-calpain and DNA were visualized by confocal laser-scanning microscopy. Cross-sections through the egg meiotic spindle (B, E and $\mathrm{H})$. Cross-sections at the equatorial plane of the egg (C, F and I). Light microscopy (A, D and G). Egg meiotic spindle (white arrow). m-calpain translocated from egg cortex toward membrane (yellow arrow). Bar $=10 \mu \mathrm{m}$.

spatial and temporal framework for potential participation in reorganization of cytoskeletal components, as has also been shown in other cell types (Hood et al. 2003).

It is well established that unique cellular mechanisms for lowering the supraphysiological requirements of $\left[\mathrm{Ca}^{2+}\right]_{\mathrm{i}}$ are involved in the activation of calpain in vitro. Among them are translocation of calpain to the membrane area and the association with phospholipids (Saido et al. 1992) or interaction with protein coactivators (Melloni et al. 1998). Another means of calpain activation that has been previously documented is an escape from calpastatin. It has been suggested that, in vivo, calpain eludes calpastatin by associating with the plasma membrane, thus being able to express its proteolytic activity (Tompa et al. 2002, Hood et al. 2003, Todd et al. 2003). The calpaincalpastatin is an intriguing complex in which calpastatin is a negative regulator of the proteinase, but at the same time can be subjected to digestion by calpains (Salamino et al. 1997). We have herein demonstrated a unique counter translocation of $\mathrm{m}$-calpain and calpastatin between the egg membrane and the egg cortex. This observation may reflect an essential step in the process of calpain activation throughout egg activation that is required by calpain to exert its proteolytic activity.

\section{Acknowledgements}

The authors are grateful to Professor Nechama Kosower for her valuable professional advice, to Dr Leonid Mittelman for his excellent technical assistance at the confocal microscope and to Ruth Kaplan-Kraicer for technical help and advice. The authors declare that there is no conflict of interest that would prejudice the impartiality of this scientific work.

\section{References}

Alexa A, Tompa P, Baki A, Vereb G \& Friedrich P 1996 Mutual protection of microtubule-associated protein 2 (MAP2) and cyclic AMP-dependent protein kinase II against mu-calpain. Journal of Neuroscience Research 44 438-445.

Arthur JS \& Crawford C 1996 Investigation of the interaction of m-calpain with phospholipids: calpain-phospholipid interaction. Biochimica et Biophysica Acta 1293 201-206.

Averna M, Tullio RD, Salamino F, Melloni E \& Pontremoli S 1999 Phosphorylation of rat brain calpastatin by protein kinase C. FEBS Letters 450 13-16.

Averna M, Tullio R, Passalacqua M, Salamino F, Pontremoli S \& Melloni E 2001 Changes in intracellular calpastatin localization are mediated by reversible phosphorylation. Biochemical Journal $35425-30$.

Barnoy S, Zipser Y, Glaser T, Grimberg Y \& Kosover NS 1999 Association of calpain $\left(\mathrm{Ca}^{+2}\right.$-dependent thiol protease) with its endogenous inhibitor calpastatin in myoblasts. Journal of Cellular Biochemistry 74 522-531.

Ben-Aharon I, Haim K, Shalgi R \& Ben-Yosef D 2005 Expression and possible involvement of calpain isoforms in mammalian egg activation. Reproduction 130 165-175. 
Ben-Yosef D \& Shalgi R 1998 Early ionic events in activation of the mammalian egg. Reviews of Reproduction 3 96-103.

Ben-Yosef D, Oron Y \& Shalgi R 1993 Prolonged, repetitive calcium transients in rat oocytes fertilized in vitro and in vivo. FEBS Letters $331239-242$.

Ben-Yosef D, Oron Y \& Shalgi R 1995 Low temperature and fertilization induced $\mathrm{Ca}^{2+}$ changes in rat eggs. Molecular Reproduction and Development 42 122-129.

Billger M, Wallin M \& Karlsson JO 1988 Proteolysis of tubulin and microtubule-associated proteins 1 and 2 by calpain I and II. Difference in sensitivity of assembled and disassembled microtubules. Cell Calcium 9 33-44.

Carragher NO, Westhoff MA, Riley D, Potter DA, Dutt P, Elce JS, Greer PA \& Frame MC 2002 v-Src-induced modulation of the calpain-calpastatin proteolitic system regulates transformation. Molecular and Cellular Biology 22 257-269.

Dandekar P \& Talbot P 1992 Perivitelline space of mammalian oocyte: extracellular matrix of unfertilized oocytes and formation of cortical granule envelope following fertilization. Molecular Reproduction and Development 31 135-143.

Dayton WR, Goll DE, Zeece MG, Robson RM \& Reville WJ 1976a A $\mathrm{Ca}^{2+}$-activated protease possibly involved in myofibrillar protein turnover. Purification from porcine muscle. Biochemistry 15 2150-2158.

Dayton WR, Reville WJ, Goll DE \& Stromer MH 1976 A Ca $^{2+}$-activated protease possibly involved in myofibrillar protein turnover. Partial characterization of the purified enzyme. Biochemistry 15 2159-2167.

Ducibella T 1991 Mammalian egg cortical granules and the cortical reaction. In Elements of Mammalian Fertilization, 1 pp 205-321. Ed. PM Wassarman. Boca Raton, Boston: CRC Press.

Eliyahu E \& Shalgi R 2002 A role for protein kinase c during rat egg activation. Biology of Reproduction 67 189-195.

Eliyahu E, Tsaadon A, Shtraizent N \& Shalgi R 2005 The involvement of protein kinase $C$ and actin filaments in cortical granule exocytosis in the rat. Reproduction 129 161-170.

Fischer Ii, Romano-Clarke G \& Grynspan F 1991 Calpain-mediated proteolysis of microtubule associated proteins MAP1B and MAP2 in developing brain. Neurochemical Research 16 891-898.

Fissore RA, Dobrinsky JR, Balise JJ, Duby RT \& Robl JM 1992 Patterns of intracellular $\mathrm{Ca}^{+2}$ concentrations in fertilized bovine eggs. Biology of Reproduction 47 960-969.

Geesink GH, Nonneman D \& Koohmaraie M 1998 An improved purification protocol for heart and skeletal muscle calpastatin reveals two isoforms resulting from alternative splicing. Archives of Biochemistry and Biophysics 356 19-24.

Glading A, Lauffenburger DA \& Wells A 2002 Cutting to the chase: calpain proteases in cell motility. Trends in Cell Biology 12 46-54.

Goll DE, Thompson VF, Taylor RG, Ouali A \& Chou R-GR 1999 The calpain system in muscle tissue. In Calpain: Pharmacology and Toxicology of Calcium-Dependent Protease, pp 127-160. Eds KKW Wang \& P-W Yuen. Philadelphia: Taylor \& Francis.

Goll DE, Thompson VF, Wei Wei HL \& Cong J 2003 The calpain system. Physiological Reviews 83 731-801.

Hood JL, Logan BB, Sinai AP, Brooks WH \& Roszman TL 2003 Association of the calpain/calpastatin system with subcellular organelles. Biochemical and Biophysical Research Communication 310 1200-1212.

Johnson GV \& Foley VG 1993 Calpain-mediated proteolysis of microtubule-associated protein 2 (MAP2) is inhibited by phosphorylation by cAMP-dependent protein kinase, but not by $\mathrm{Ca}^{2+} /$ calmodulin-dependent protein kinase II. Journal of Neuroscience Research 34 642-647.

Kline D \& Kline JT 1992 Repetitive calcium transients and the role of calcium in exocytosis and cell cycle activation in the mouse egg. Developmental Biology 149 80-89.

Kline D \& Stewart-Savage JS 1994 The timing of cortical granule fusion, content dispersal, and endocytosis during fertilization of the hamster egg: an electrophysiological and histochemical study. Developmental Biology 162 277-287.

Kuo WN, Ganesan U, Davis DL \& Walbey DL 1994 Regulation of the phosphorylation of calpain II and its inhibitor. Molecular and Cellular Biochemistry 136 157-161.

Lane RD, Allan DM \& Mellgren RL 1992 A comparison of the intracellular distribution of $\mu$-calpain, $\mathrm{m}$-calpain, and calpastatin in proliferating human A431 cells. Experimental Cell Research 203 $5-16$.

Lorca T, Galas S, Fesquet D, Devault A, Cavadore JC \& Doree M 1991 Degradation of the proto-oncogene product p39mos is not necessary for cyclin proteolysis and exit from meiotic metaphase: requirement for a $\mathrm{Ca}(2+)$-calmodulin dependent event. $E M B O$ Journal 10 2087-2093.

Melloni E \& Pontremoli S 1989 The calpains. Trends in Neurosciences 12 438-444.

Melloni E, Michetti M, Salamino F, Minafra R \& Pontremoli S 1996 Modulation of the calpain autoproteolysis by calpastatin and phospholipids. Biochemical and Biophysical Research Communication 229 193-197.

Melloni E, De Tullio R, Averna M, Tedesco I, Salamino F, Sparatore B \& Pontremoli S 1998 Properties of calpastatin forms in rat brain. FEBS Letters 431 55-58.

Michetti M, Viotti PL, Melloni E \& Ponttemoli S 1991 Mechanism of action of the calpain activator protein in rat skeletal muscle. European Journal of Biochemistry 202 1177-1180.

Miyazaki S 1988 Inositol 1,4,5-triphosphate-induced calcium release and guanine nucleotide-binding protein-mediated periodic calcium rises in golden hamster eggs. Journal of Cell Biology 106 $345-353$

Miyazaki S 1991 Repetitive calcium transients in hamster oocytes. Cell Calcium 12 205-216.

Miyazaki S, Shirakawa H, Nakada K, Honda Y, Yuzaki M \& Nakada S 1992 Antibody to inositol triphosphate receptor blocks thimerosalenhanced $\mathrm{Ca}^{+2}$-induced $\mathrm{Ca}^{+2}$ release and $\mathrm{Ca}^{+2}$ oscillations in hamster eggs. FEBS Letters 309 180-184.

Murachi T 1989 Intracellular regulatory system involving calpain and calpastatin. Biochemistry International 18 263-294.

Parr T, Sensky PL, Bardsley RG \& Buttery PJ 2001 Calpastatin expression in porcine cardiac and skeletal muscle and partial gene structure. Archives of Biochemistry and Biophysics 395 $1-13$.

Pettigrew LC, Holtz ML, Craddock SD, Minger SL, Hall N \& Geddes JW 1996 Microtubular proteolysis in focal cerebral ischemia. Journal of Cerebral Blood Flow and Metabolism 16 1189-1202.

Saido TC, Shibata M, Takenawa T, Murofushi H \& Suzuki K 1992 Positive regulation of mu-calpain action by polyphosphoinositides. Journal of Biological Chemistry 267 24585-24590.

Salamino F, Averna M, Tedesco I, De Tullio R, Melloni E \& Pontremoli S 1997 Modulation of rat brain calpastatin efficiency by post-translational modifications. FEBS Letters 412 433-438.

Santella L, Kyozuka K, De Riso L \& Carafoli E 1998 Calcium, protease action and the regulation of the cell cycle. Cell Calcium $\mathbf{2 3}$ $123-130$.

Sun FZ, Hoyland J, Houng X, Mason W \& Moor RM 1992 A comparison of intracellular changes in porcine eggs after fertilization and electroactivation. Development 115 947-956.

Suzuki K \& Sorimachi H 1998 A novel aspect of calpain activation. FEBS Letters 433 1-4.

Takano E, Ueda M, Tsunekawa S, Murakami T, Maki M, Hatanaka M \& Murachi T 1991 Molecular diversity of erythrocyte calpastatin. Biomedica Biochimica Acta 50 517-521.

Takano E, Nosaka T, Lee WJ, Nakamura K, Takahashi T, Funaki M, Okada H, Hatanaka M \& Maki M 1993 Molecular diversity of calpastatin in human erythroid cells. Archives of Biochemistry and Biophysics 303 349-354.

Takano J, Watanabe M, Hitomi K \& Maki M 2000 Four types of calpastatin isoformes with distinct amino-terminal sequences are 
specific by alternative first exons and differentially expressed in mouse tissues. Journal of Biochemistry 128 83-92.

Talmor A, Kinsey WH \& Shalgi R 1998 Expression and immunolocalization of $559^{\mathrm{c}-\mathrm{fyn}}$ tyrosine kinase in rat eggs. Developmental Biology 194 38-46.

Todd B, Moore D, Deivanayagam CCS, Lin GD, Chattopadhyay D, Maki M, Wang KKW \& Narayana SVL 2003 A structural model for the inhibition of calpain by calpastatin: crystal structures of the native domain $\mathrm{VI}$ of calpain and its complexes with calpastatin peptide and a small molecule inhibitor. Journal of Molecular Biology 328 131-146.

Tompa P, Mucsi Z, Orosz G \& Friedrich P 2002 Calpastatin subdomains $\mathrm{A}$ and $\mathrm{C}$ are activators of calpain. Journal of Biological Chemistry 277 9022-9026.

Tullio RD, Passalacqua M, Averna M, Salamino F, Melloni E \& Pontremoli S 1999 Changes in intracellular localization of calpastatin during calpain activation. Biochemical Journal 343 467-472.
Tullio RD, Averna M, Salamino F, Pontremoli S \& Melloni E 2000 Differential degradation of calpastatin by $\mu$ - and $\mathrm{m}$-calpain in $\mathrm{Ca}^{+2}$-enriched human neuroblastoma LAN-5 cells. FEBS Letters $47517-21$.

Watanabe N, Vande Woude GF, Ikawa Y \& Sagata N 1989 Specific proteolysis of the c-mos proto-oncogene product by calpain on fertilization of Xenopus eggs. Nature 342 505-511.

Wei W, Li H, Cong J, Thompson VF \& Goll DE 2002 Immunoaffinity purification of calpastatin and calpastatin constructs. Biochimica et Biophysica Acta 1597 97-106.

Received 26 July 2005

Accepted 19 August 2005 